\title{
Burkitt Lymphoma with Multiorgan Involvement
}

\author{
${ }^{1}$ Venus Kumar, ${ }^{2} \mathrm{HR}$ Chandrashekhar, ${ }^{3}$ Suresh Hanagavadi
}

\begin{abstract}
Burkitt lymphoma $(B L)$ is classified as a poorly differentiated lymphocytic lymphoma of B lymphocytes. It mainly affects children. It is one of the rapidly growing tumors in humans, with profuse proliferation. It is a rare malignancy comprised of only $0.76 \%$ of solid malignant tumors among Indian children.

Symptoms occur because of rapid turnover of the mature B lymphocytes with involvement of the extranodal sites and involvement of adjacent organs. Initially, this tumor was identified in Africans. The cause of this tumor is uncertain, but shows strong evidence with Epstein-Barr virus (EBV) in its development. $A$ case of $B L$ with multiorgan involvement in a 7-year-old girl was reported, which was confirmed by immunohistochemistry (IHC).
\end{abstract}

Keywords: B cell, Burkitt lymphoma, Immunohistochemistry, Lymphoma.

How to cite this article: Kumar V, Chandrashekhar HR, Hanagavadi S. Burkitt Lymphoma with Multiorgan Involvement. Int J Recent Surg Med Sci 2018;4(1):24-28.

Source of support: Nil

Conflict of interest: None

\section{INTRODUCTION}

Burkitt lymphoma is a rare highly aggressive lymphoma firstly identified and described by Denis Parsons Burkitt, a surgeon in 1958 in Africa, areas which are endemic for malaria. Histological similarity was found between BL occurring in nonendemic areas and in endemic areas. ${ }^{1}$

In 1982, the c-myc gene was found showing abnormal production of B lymphocytes. This gene showed translocation between long arms of chromosome 8 with 14 and, to a lesser extent, between chromosomes 8,22 , and 2 . $^{2}$ There are three subtypes of BL. The endemic variant (African type) is strongly linked with EBV. Patient presents with involvement of jaw, facial bones (orbit), cervical lymph nodes, distal ileum, cecum, ovaries, kidney, breast, and skeletal. ${ }^{3}$

The sporadic type (non-African) is sometimes associated with EBV. Patient presents with abdominal tumors associated with bone marrow affection, bowel obstruction secondary to ileocecal intussusception due

\footnotetext{
${ }^{1}$ Postgraduate Student, ${ }^{2,3}$ Professor

${ }^{1-3}$ Department of Pathology, J.J.M Medical College, Davangere Karnataka, India

Corresponding Author: Venus Kumar, Postgraduate Student Department of Pathology, J.J.M Medical College, Davangere Karnataka, India, Phone: +919742836778, e-mail:venus_kmr@ yahoo.co.in
}

to tumor growth. Generalized lymphadenopathy is rare. Immunodeficiency-related BL associated with human immunodeficiency virus infection presents with nodal and bone marrow involvement. ${ }^{4}$

\section{CASE REPORT}

We report a case of a 7-year-old Indian girl, referred to the Department of Pathology, J.J.M Medical College, presenting with complaints of abdominal pain and distention since 15 days. On physical examination, she was afebrile, respiratory rate was $25 / \mathrm{min}$, pulse rate of $94 / \mathrm{min}$, and blood pressure was 90/60 $\mathrm{mm} \mathrm{Hg}$.

On systemic examination, cardiovascular system, respiratory system, and central nervous system (CNS) were normal. On per-abdomen examination, the abdomen was soft, nontender, all quadrants did not move equally well with respiration, and a mass per abdomen was palpated measuring $10 \times 2 \mathrm{~cm}$ around the umbilicus; there was no fluid thrill and normal bowel sounds were present. On investigating, her complete hemogram showed hemoglobin of $9.8 \mathrm{gm} \%$, total leukocyte count of 12,270 cells/ cumm, platelet count of 4.35 lakhs/cumm, and peripheral smear showed microcytic hypochromic anemia.

At the time of examining the peripheral smear, there was no evidence of spillage of lymphoma cells in circulating blood. Other parameters done were lactate dehydrogenase (LDH), which was elevated to 2,594 IU/L, and alpha-fetoprotein was normal: $2 \mathrm{ng} / \mathrm{mL}$. Ultrasonography (USG) of abdomen and pelvis revealed two cystic lesions, one measuring $7 \times 6 \times 2 \mathrm{~cm}$ with altered internal echoes in the central abdomen and the other clear cystic lesion in pelvis measuring $8 \times 4 \times 3 \mathrm{~cm}$ (Probable diagnosis mesenteric cysts). For further evaluation, computed tomography of abdomen and pelvis was done which confirmed the USG findings (well-defined cystic lesion in midline in pelvis measuring $6.2 \times 3.8 \times 8 \mathrm{~cm}$, a fat density solid component noted within the cystic lesion measuring $1 \times 1 \times 0.8 \mathrm{~cm}$; uterus and ovaries were not seen separately) (Fig. 1).

Laparotomy was done. Intraoperatively, right and left ovaries were found to be enlarged which were firm in consistency measuring $3 \times 3$ and $6 \times 4 \mathrm{~cm}$ respectively. A hard mass with multiple lymph node enlargement was found in the mesentery of the distal ileum.

Scrape and imprint smears of both ovaries and abdominal lymph nodes were taken intraoperatively. Subsequently, lymph node biopsy of both ovaries and 

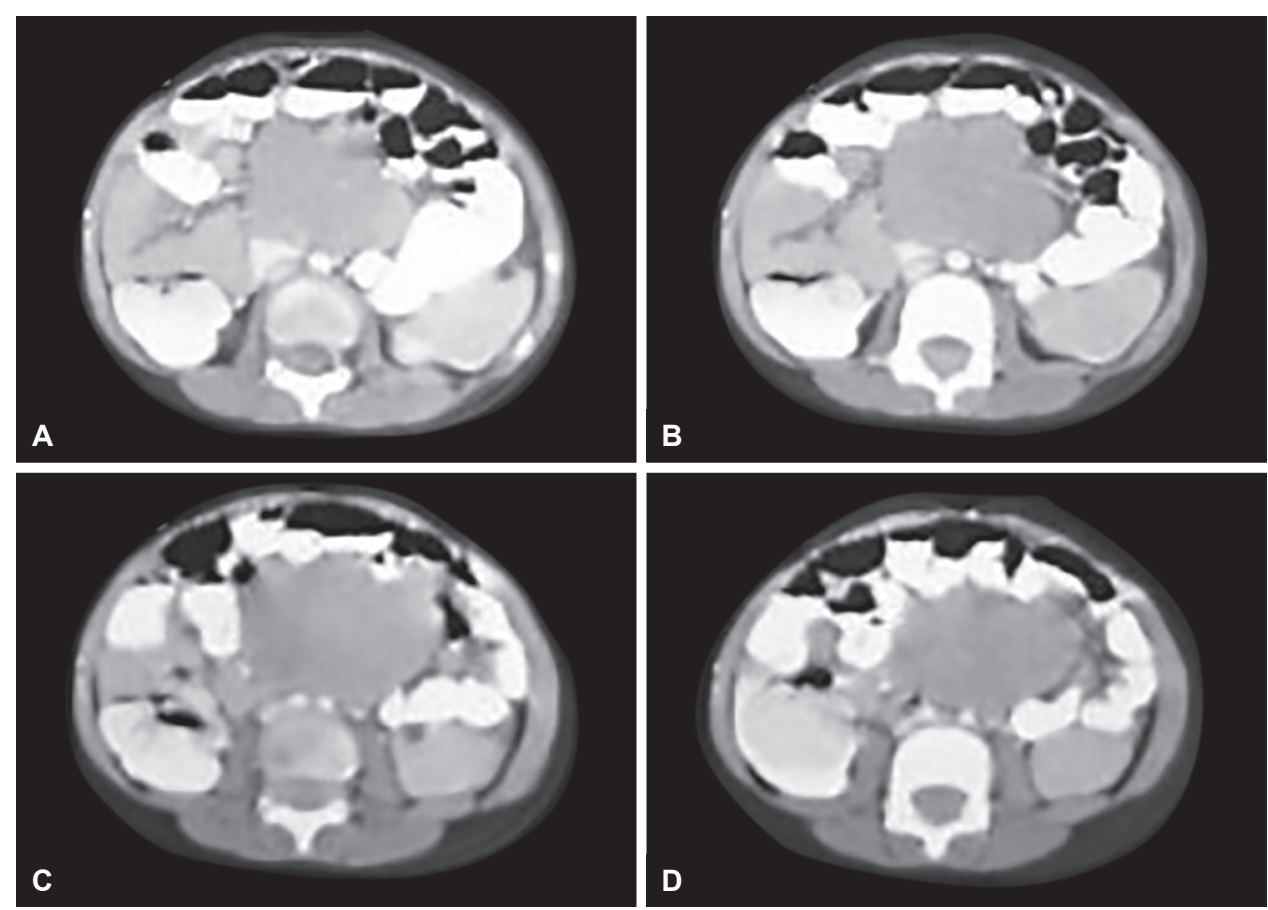

Figs $1 \mathrm{~A}$ to $\mathrm{D}$ : Axial contrast-enhanced computed tomography image of the pelvis showing a well-defined midline cystic lesion with minimal enhancement

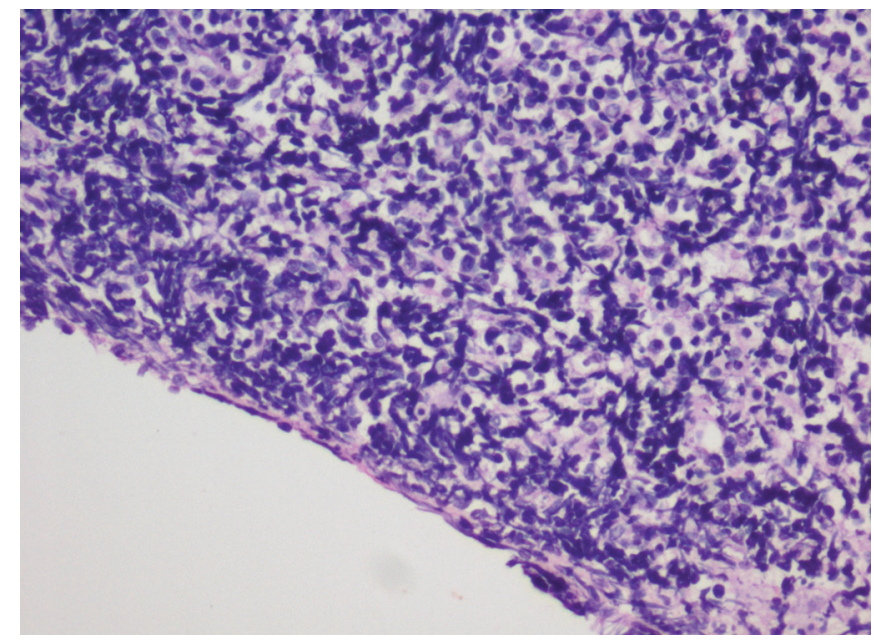

Fig. 2: Atypical lymphoid infiltrate seen with the periphery showing normal ovarian stroma. Hematoxylin and eosin (40x)

omental specimens was sent for histopathology study, and peritoneal fluid was sent for fluid cytology analysis. Bone marrow aspirate was also performed intraoperatively. Scrape, imprint cytology, biopsy of all specimens, and bone marrow aspirate showed features which were suggestive of non-Hodgkin lymphoma-Burkitt type.

Lymph node biopsy showed effaced architecture replaced by sheets of intermediate-sized cells having high nuclear-cytoplasmic ratio, open chromatin, few nucleoli and increased mitotic activity, and areas of apoptosis with a classical starry sky appearance (Fig. 2). Similar features were seen on ovarian and omental tissue (Figs 3 to 8). Immunohistochemical markers performed for CD20 was

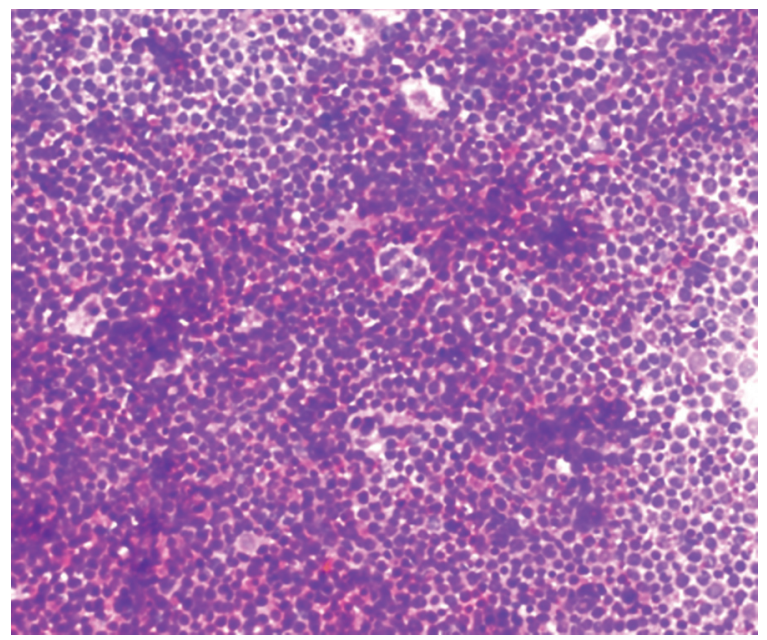

Fig. 3: Scrape cytology of the ovarian tissue showing hypercellular smears with numerous macrophages within the tumor giving a characteristic "starry sky" appearance. Hematoxylin and eosin (10x)

positive and negative for $\mathrm{CD} 3$, confirming that it was a B-cell lymphoma (Figs 9 to 12).

Based on the clinical, hematologic, radiographic, cytomorphology, histopathology, and immunohistochemical investigations, the final diagnosis of BL was considered.

\section{DISCUSSION}

Burkitt lymphoma is defined by the updated World Health Organization classification as the high-grade aggressive B-cell lymphoma. ${ }^{5}$ It is a rapidly growing human tumor with a doubling time of less than 24 hours. ${ }^{6}$ This tumor accounts for more than $50 \%$ of all childhood cancers in Africa. 


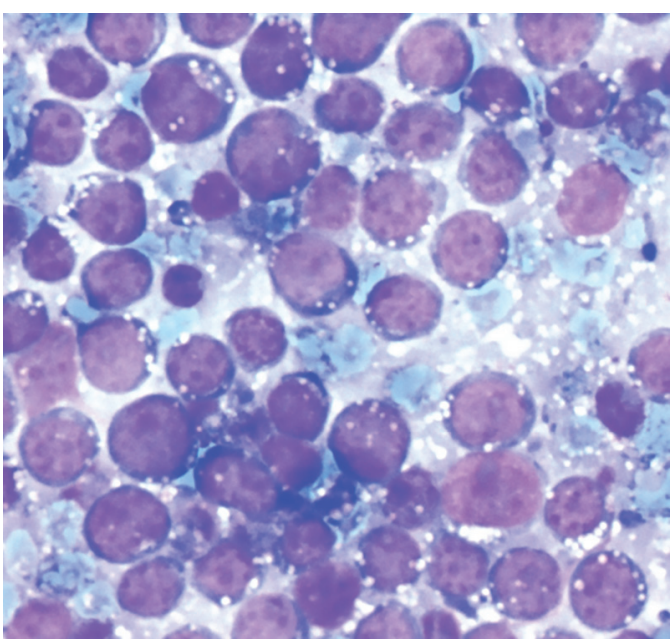

Fig. 4: Scrape cytology showing monotonous population of medium-sized cells with nuclear and cytoplasmic vacuolations. Giemsa (40x)

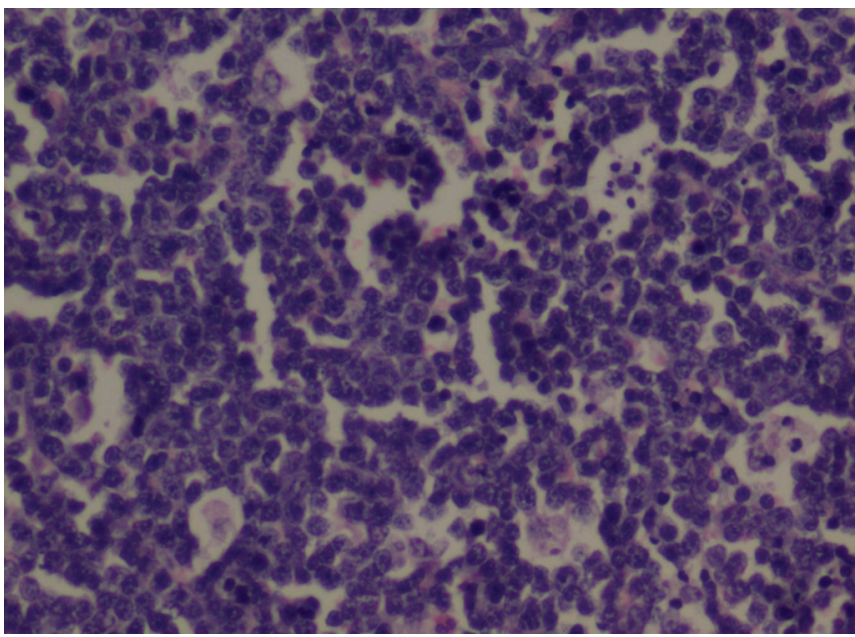

Fig. 6: Lymph node biopsy showing diffuse infiltrate of atypical lymphoid cells with a prominent starry sky pattern because of presence of multiple tingible body macrophages. Hematoxylin and eosin $(40 x)$

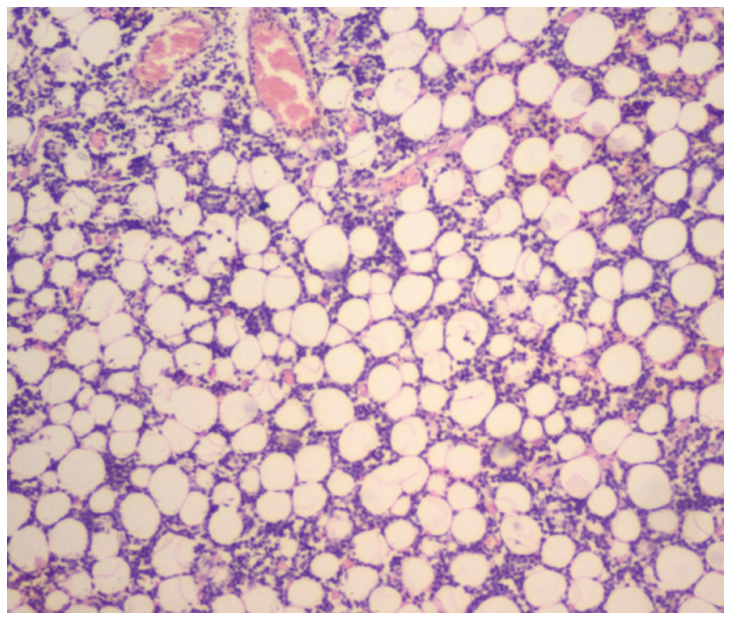

Fig. 8: Omental biopsy showing similar features as that of lymph node and ovary. Hematoxylin and eosin (40x)

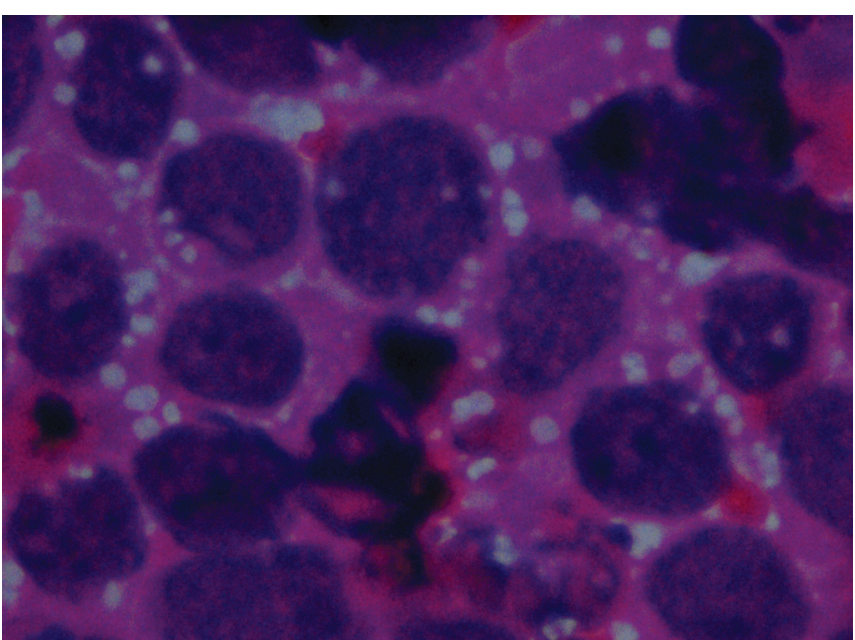

Fig. 5: Scrape showing prominent nuclear and cytoplasmic vacuolations. Hematoxylin and eosin (100x)

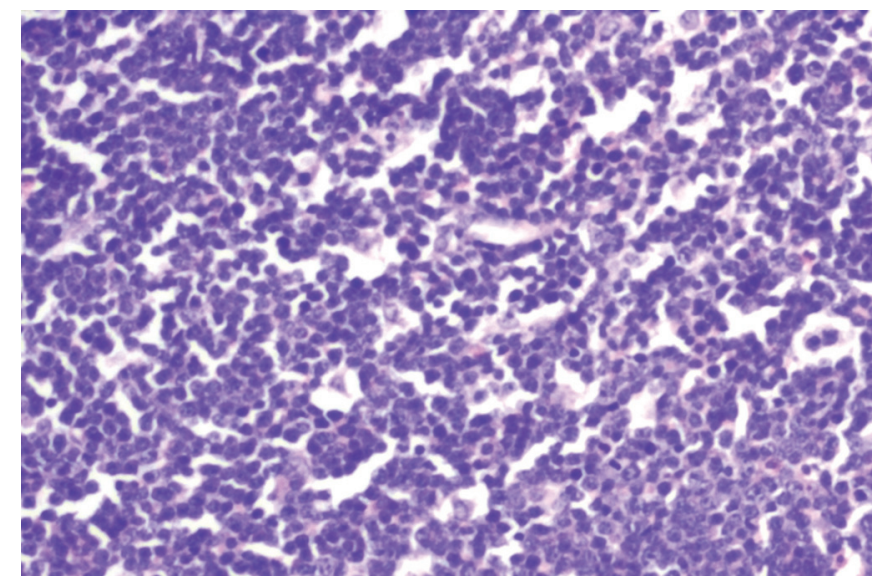

Fig. 7: Ovarian tissue showing diffuse infiltrate of atypical lymphoid cells with a prominent starry sky pattern because of presence of multiple tingible body macrophages. Hematoxylin and eosin (40x)

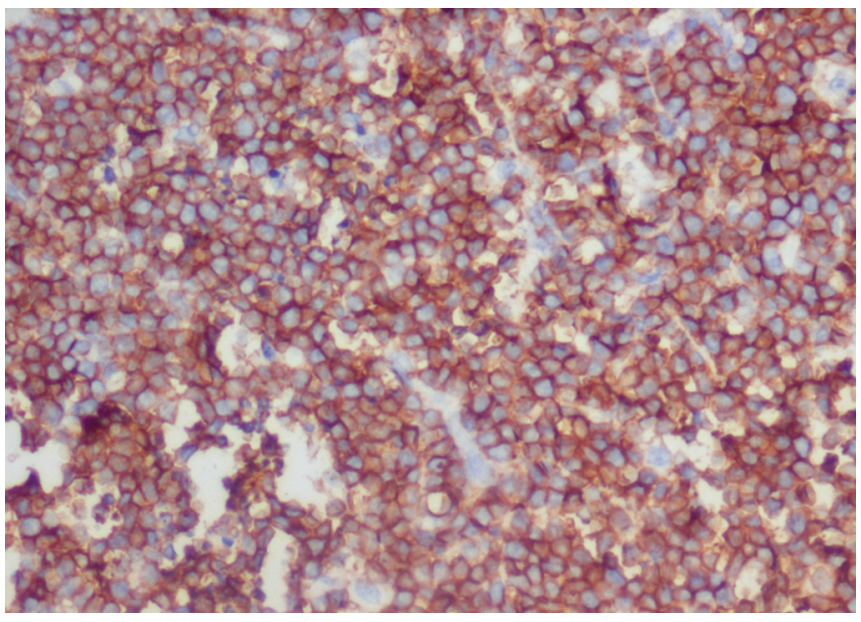

Fig. 9: Lymph node tissue showing diffuse immunostaining for CD20 (B-cell marker) 


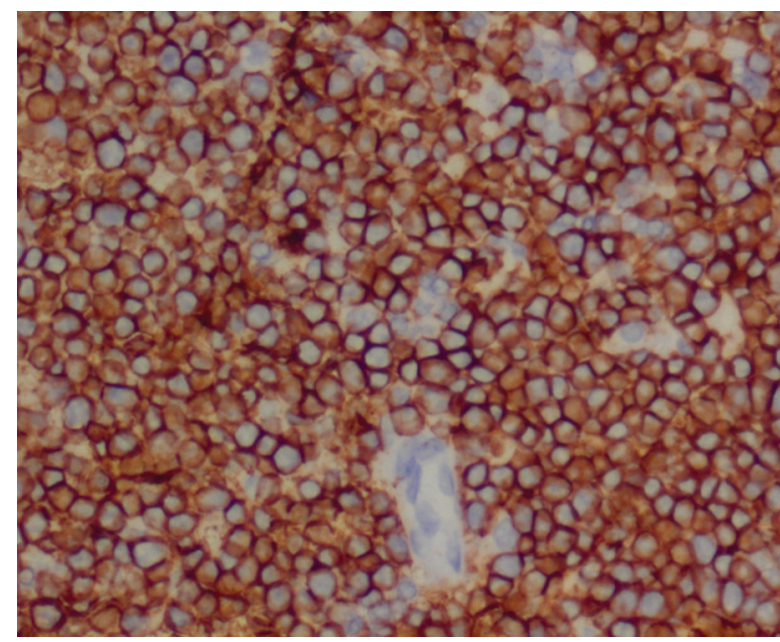

Fig. 10: Ovarian tissue showing diffuse immunostaining for CD20 (B-cell marker)

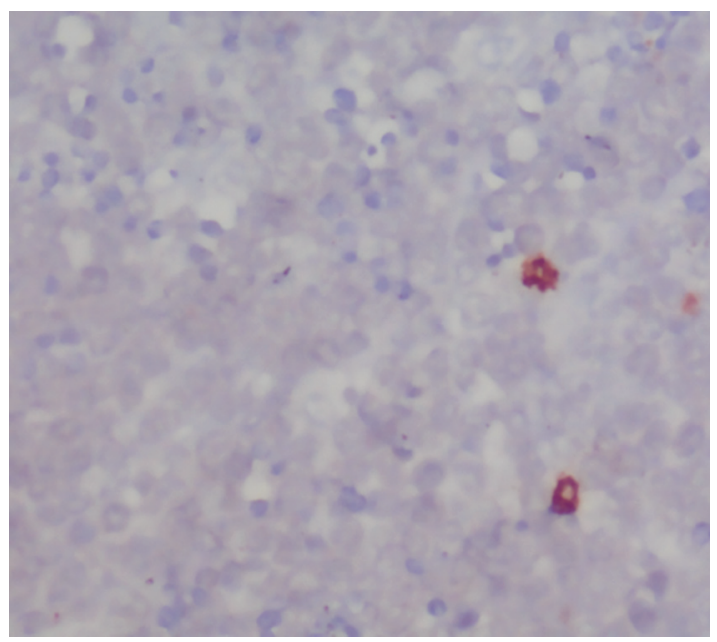

Fig. 12: Lymph node tissue showing negative immunostaining for CD3 (T-cell marker)

In non-African countries, it accounts for less than $2 \%$ of all cases of NHL. Isolated cases of BL are reported intermittently from all over India. However, very few large related studies have been done in children and young adults. From the available report by Naresh et al, ${ }^{7}$ out of 2,773 lymphoma cases, 50 cases, i.e., $1.8 \%$, were of BL. i.e., $1.8 \%$, were of BL. ${ }^{6}$ In order to know the true incidence of BL in Indian children and young adults, a large study needs to be undertaken. The role of EBV in BL is not well understood.

This virus preferentially infects B-cells via the C3d complement receptor CD2. ${ }^{5}$ In Africa, BL usually presents in the jaw, whereas sporadic BL presents as abdominal mass. However, in India, clinical presentation of BL is intermediate between the sporadic and endemic types. In a study conducted by VP Choudhary et al, ${ }^{8}$ they found that BL in India presents with equal involvement of jaw and abdomen in almost equal number and concluded that it is the third mode of clinical presentation. A separate

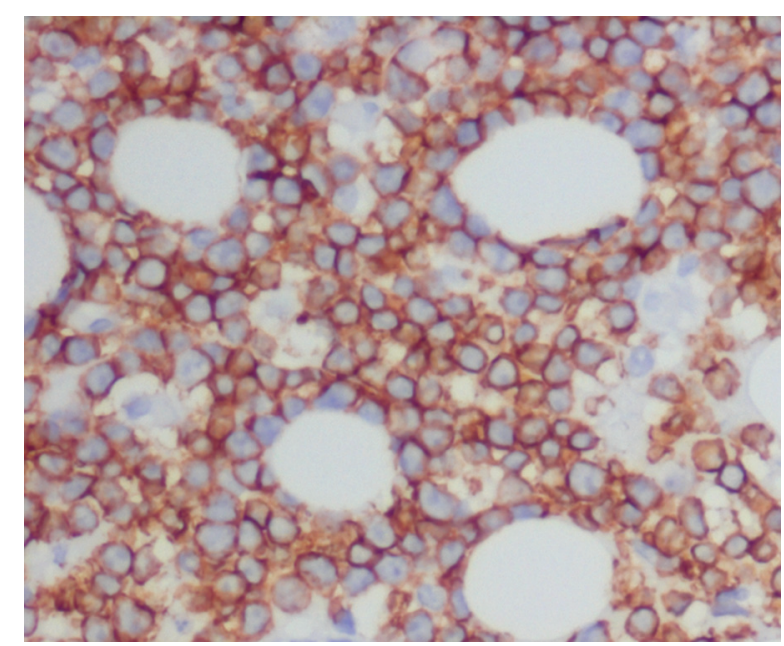

Fig. 11: Omental tissue showing diffuse immunostaining for CD20 (B-cell marker)

staging system for BL has been developed by Zeigler (1981), whereas Levine et al (1982) classified the cases of the American BL as follows':

- Stage I: Single tumor mass (extra-abdominal 1A or abdominal 2A).

- Stage II: two separate tumor masses on the same side of the diaphragm.

- Stage III: involvement of more than two separate masses or disease on both sides of the diaphragm.

- Stage IV: pleural effusion, ascites, or involvement of the CNS or bone marrow.

Based on the staging proposed by Levine et al, the present case can be grouped as stage IV, as there is a bone marrow involvement. Patients with any of the above three clinical variants are at higher risk for spread to the CNS and bone marrow. The bone marrow is positive in 30 to $38 \%$, and the CNS is involved in 13 to $17 \%$ of adult cases. ${ }^{1}$ In a study of children with disseminated disease, $12 \%$ had CNS involvement, and $22 \%$ had marrow involvement. ${ }^{10}$ The most important prognostic features for BL are yet to be found, but some features that have been associated with adverse outcome in adults and children include more age, advanced stage, poor performance status, bulky disease, and high LDH, and CNS or marrow involvement has poor prognosis. Among pediatric patients, a poorer prognosis is associated with age over 15 years. ${ }^{11}$ The closest differential diagnosis of BL is diffuse large B-cell lymphoma. There is no single test or marker which can differentiate between these two lymphomas. Hence, various approaches are required which include cytomorphological findings, IHC/biopsy with IHC, genetic studies, and clinical correlation to differentiate and establish a diagnosis of BL. Intermediate-sized cells with clumped chromatin, and two to three prominent nucleoli, cytoplasmic vacuolation, and scattered tingible body macrophages form characteristic cytomorphology 
of BL. Prototypical immunophenotype of BL includes CD20+, CD10+, BCL6+, BCL2-, TdT-, and sIgM+ with virtually all cells $\mathrm{Ki}-67+{ }^{12}$ Immunophenotypic analysis in the present case showed neoplastic cells positive for CD20 and negative for CD3.

\section{CONCLUSION}

Burkitt lymphoma is a very rare, fast-progressing malignant tumor of childhood with diverse clinical features. Although it occurs infrequently among Indian population, it does not mean that it should deter the clinician from including it as a part of differential diagnosis. Hence, our findings suggested and emphasized that BL must be suspected in differential diagnosis of a child presenting with large intra-abdominal mass and histological diagnosis should be established as soon as possible along with the IHC markers for confirmation of the diagnosis.

\section{REFERENCES}

1. Blum KA, Lozanski G, Byrd JC. Adult Burkitt leukemia and lymphoma. Blood 2004 Nov;104(10):3009-3020.

2. Gerbitz A, Mautner J, Geltinger C, Hörtnagel K, Christoph B, Asenbauer H, Klobeck G, Polack A, Bornkamm GW. Deregulation of the proto-oncogene c-myc through $\mathrm{t}(8 ; 22)$ translocation in Burkitt's lymphoma. Oncogene 1999 Mar;18(9): 1745-1753.

3. Burkitt DP. The discovery of Burkitt's lymphoma. Cancer 1983 May;51(10):1777-1786.
4. Bellan C, Lazzi S, De Falco G, Nyongo A, Giordano A, Leoncini L. Burkitt's lymphoma: new insights into molecular pathogenesis. J Clin Pathol 2003 Mar;56(3):188-192.

5. Ugar DA, Bozkaya S, Karaca I, Tokman B, Pinarli FG. Childhood craniofacial Burkitt's lymphoma presenting as maxillary swelling: report of a case and review of literature. J Dent Child (Chic) 2006 Jan-Apr;73(1):45-50.

6. Wood, RE. Malignant diseases of the jaws. In: White SC, Pharaoli MJ, editors. Oral radiology: principles and interpretations. 5th ed. St. Loius (MO): Mosby; 2004. pp. 450-451.

7. Naresh KN, Srinivas V, Soman CS. Distribution of various subtypes of non Hodgkin's lymphoma in India: a study of 2773 lymphomas using R.E.A.L. and WHO classifications. Ann Oncol 2000 Jan;11(Suppl 1):63-67.

8. Choudhary VP, Agarwal RK, Marwah RK. Characteristics of Burkitt's lymphoma in India. Indian J Pediatr 1987 Nov-Dec;54(6):859-862.

9. Zeigler JL, Morrow RH Jr, Fass L, Kyalwazi SK, Carbone PP. Treatment of Burkitt's tumour with cyclophosphamide. Cancer 1970 Aug;26(2):474-484.

10. CairoMS,SpostoR,PerkinsSL,Meadows AT,Hoover-ReganML, Anderson JR, SiegelSE, Lones MA, Tedeschi-BlokN,Kadin ME, et al. Burkitt's and Burkitt-like lymphoma in children and adolescents: a review of the Children's Cancer Group experience. Br J Haematol 2003 Feb;120(4):660-670.

11. Bowman WP, Shuster JJ, Cook B, Griffin T, Behm F, Pullen J, Link M, Head D, Carroll A, Berard C, et al. Improved survival for children with B-cell acute lymphoblastic leukemia and stage IV small noncleaved-cell lymphoma: a pediatric oncology group study. J Clin Oncol 1996 Apr;14(4):1252-1261.

12. Ferry JA. Burkitt's lymphoma: clinicopathological features and differential diagnosis. Oncologist 2006 Apr;11(4):375-383. 